OPEN ACCESS

Edited by:

Goetz Hensel,

Leibniz-Institut für Pflanzengenetik und Kulturpflanzenforschung (IPK),

Germany

Reviewed by:

Renu Deswal,

University of Delhi, India

Raffaella Balestrini,

Italian National Research Council

(IPSP-CNR), Italy

*Correspondence:

Silvana Creste

screste@iac.sp.gov.br

Specialty section:

This article was submitted to

Plant Biotechnology,

a section of the journal

Frontiers in Plant Science

Received: 09 October 2018 Accepted: 16 January 2019

Published: 13 February 2019

Citation:

Andrade $L M$, Peixoto-Junior RF, Ribeiro RV, Nóbile PM, Brito MS,

Marchiori PER, Carlin SD,

Martins APB, Goldman MHS, Llerena JPP, Fregonesi C, Perecin D, Nebó JFCO, Figueira A, Benatti TR,

Silva J, Mazzafera $P$ and Creste $S$

(2019) Biomass Accumulation and Cell Wall Structure of Rice Plants

Overexpressing a Dirigent-Jacalin of Sugarcane (ShDJ) Under Varying

Conditions of Water Availability.

Front. Plant Sci. 10:65.

doi: 10.3389/fpls.2019.00065

\section{Biomass Accumulation and Cell Wall Structure of Rice Plants Overexpressing a Dirigent-Jacalin of Sugarcane (ShDJ) Under Varying Conditions of Water Availability}

Larissa Mara Andrade 1,2, Rafael Fávero Peixoto-Junior ${ }^{1,2}$, Rafael Vasconcelos Ribeiro ${ }^{3}$, Paula Macedo Nóbile', Michael Santos Brito ${ }^{1,4}$, Paulo Eduardo Ribeiro Marchiori5,6, Samira Domingues Carlin', Alexandre Palma Boer Martins ${ }^{1,2}$, Maria Helena S. Goldman', Juan Pablo Portilla Llerena ${ }^{3}$, Caroline Fregonesi', Dilermando Perecin ${ }^{8}$, João Felipe Carlos de Oliveira Nebó ${ }^{9}$, Antonio Figueira ${ }^{9}$, Thiago Romanos Benatti ${ }^{10}$, Jorge da Silva ${ }^{10}$, Paulo Mazzafera ${ }^{3}$ and Silvana Creste ${ }^{1 *}$

${ }^{1}$ Instituto Agronômico (IAC), Centro de Cana, Ribeirão Preto, Brazil, ${ }^{2} P P G$ - Genética, Faculdade de Medicina de Ribeirão Preto, Universidade de São Paulo, Ribeirão Preto, Brazil, ${ }^{3}$ Department of Plant Biology, Institute of Biology, University of Campinas, Campinas, Brazil, ${ }^{4}$ Instituto de Ciência e Tecnologia, Universidade Federal de São Paulo, São José dos Campos, Brazil, ${ }^{5}$ Instituto Agronômico (IAC), Centro de Ecofisiologia e Biofísica, Campinas, Brazil, ${ }^{6}$ Departamento de Biologia, Universidade Federal de Lavras, Lavras, Brazil, ${ }^{7}$ Departamento de Biologia, Faculdade de Filosofia, Ciências e Letras de Ribeirão Preto, Universidade de São Paulo, Ribeirão Preto, Brazil, ${ }^{8}$ Faculdade de Ciências Agrárias e Veterinárias, Universidade Estadual Paulista Júlio de Mesquita Filho (UNESP), Jaboticabal, Brazil, ${ }^{9}$ Centro de Energia Nuclear na Agricultura (CENA), University of São Paulo, Piracicaba, Brazil, ${ }^{10}$ Texas A\&M Agrilife Research \& Extension Center, Weslaco, TX, United States

A sugarcane gene encoding a dirigent-jacalin, ShDJ, was induced under drought stress. To elucidate its biological function, we integrated a ShDJ-overexpression construction into the rice Nipponbare genome via Agrobacterium-mediated transformation. Two transgenic lines with a single copy gene in $T_{0}$ were selected and evaluated in both the $T_{1}$ and $T_{4}$ generations. Transgenic lines had drastically improved survival rate under water deficit conditions, at rates close to 100\%, while WT did not survive. Besides, transgenic lines had improved biomass production and higher tillering under water deficit conditions compared with WT plants. Reduced pectin and hemicellulose contents were observed in transgenic lines compared with wild-type plants under both well-watered and water deficit conditions, whereas cellulose content was unchanged in line \#17 and reduced in line \#29 under conditions of low water availability. Changes in lignin content under water deficit were only observed in line \#17. However, improvements in saccharification were found in both transgenic lines along with changes in the expression of OsNTS1/2 and OsMYB58/63 secondary cell wall biosynthesis genes. ShDJ-overexpression upregulated the expression of the OsbZIP23, OsGRAS23, OsP5CS, and OsLea3 genes in rice stems under well-watered conditions. Taken together, our data suggest that $S h D J$ has the potential for improving drought tolerance, plant biomass accumulation, and saccharification efficiency.

Keywords: water deficit, RT-qPCR, transgenic plants, overexpression, monocot plants 


\section{INTRODUCTION}

Sugarcane is a commercially important crop in tropical and subtropical regions (Inman-Bamber and Smith, 2005), and is the fifth most important crop in the world (FAOSTAT, 2013). Worldwide, sugarcane is considered the main raw material for table sugar production, and is being explored for the generation of clean and renewable energy, such as bioethanol and bioelectricity from first-generation ethanol (E1G) (Dias et al., 2011). In Brazil, the world leader in sugarcane production, the crop is cultivated over more than 9 million hectares, and the estimated production for the 2018/2019 season is around 365 million tons (CONAB, 2018).

In recent years, sugarcane production has been affected by unfavorable climatic conditions, which are increasing in frequency and intensity. Drought is an important abiotic stress that negatively impacts sugarcane productivity (Zhao and $\mathrm{Li}$, 2015). This can be, due to water shortage even in rainy seasons or to the expansion of sugarcane cultivation to non-traditional planting regions, such as the Brazilian Cerrado (droughtprone conditions). Therefore, a challenge for sugarcane breeding programs is to develop cultivars with high productivity under water scarcity.

Despite advances in the conventional breeding of sugarcane, molecular biology and genetic engineering tools now have the potential to accelerate cultivar development and crop productivity by introducing new genes or manipulating gene expression. However, a lack of genetic and molecular information on drought tolerance mechanisms and their inheritance in sugarcane has limited the development of improved cultivars. Thus, functional genomics play a relevant role in the identification of target genes for the generation of transgenic sugarcane cultivars.

To withstand conditions imposed by water deprivation, plants have developed several strategies and responses on morphological, physiological, hormonal, molecular, and biochemical levels (Fang and Xiong, 2015). Among stressresponsive pathways, hormone signaling can regulate plant growth and enhance drought tolerance (Tiwari et al., 2017). Although abscisic acid is the principal mediator of drought responses, jasmonate (JA) plays an important role under abiotic and biotic stress (Wasternack, 2007), triggering response mechanisms that may improve stress tolerance (Muñoz-Espinoza et al., 2015).

The function of JA hormone signaling in the response to biotic stress is well-understood (Wasternack, 2007; Wasternack and Hause, 2013), and its involvement in the response to drought has been suggested (Muñoz-Espinoza et al., 2015; de Ollas and Dodd, 2016). JA promotes the activation of transcription factors resulting in the expression of various JA-responsive genes (Howe, 2010). The activation of JA-responsive genes can alter the levels of various proteins involved in numerous biological processes (Pauwels et al., 2009), such as lectin synthesis (Van Damme et al., 1998; Wang and Ma, 2005; Ma et al., 2010). Lectins are carbohydrate-binding proteins found in all organisms (Vijayan and Chandra, 1999; De Schutter and Van Damme, 2015), which recognize and reversibly bind to specific sugar structures and mediate several biological reactions (Peumans and Damme, 1995;
Vijayan and Chandra, 1999). This heterogeneous group contains jacalin-related lectins (JRLs), which contain one or more JRL domains (De Schutter and Van Damme, 2015). JRLs have also been associated with an unrelated domain, and are named chimeric proteins (Jiang et al., 2010; Song et al., 2014). Several of these chimeric proteins (chimerolectins) contain domains related to stress response and defense. Of these, a C-terminal jacalin domain fused to a N-terminal dirigent (Song et al., 2014; Schutter and Van Damme, 2015) has been shown to affect a broad range of physiological functions in monocot plants (Ma, 2014; Song et al., 2014). Nobile et al. (2017) made a comprehensive characterization of proteins containing dirigent (DIR) domain in sugarcane and found $6.7 \%$ as chimeric jacalins containing DIR domains.

Monocot chimeric jacalins have been identified in maize (Esen and Blanchard, 2000), sorghum (Kittur et al., 2010), rice (Jiang et al., 2006, 2007; Hensel et al., 2016), wheat (Subramanyam et al., 2008; Ma et al., 2013), and sugarcane (Nobile et al., 2017). These proteins play important roles in both biotic and abiotic stress responses ( $\mathrm{Ma}, 2014$ ), and in the regulation of plant growth and development (Lannoo and Van Damme, 2010). In sugarcane, the exact functions of the JRL domain associated with a dirigent domain (Dirigent-Jacalin or DJ) have not yet been characterized. Despite the importance of plant JRLs, current knowledge on genome function and the regulation of JRLs in polyploid species, as in sugarcane (Saccharum spp.), remains elusive. Although several studies have addressed drought tolerance in genetically modified sugarcane (Zhang et al., 2006; Molinari et al., 2007; Kumar et al., 2014; Reis et al., 2014), the lack of well-characterized genes that guarantee satisfactory yield under water deficit conditions represents a bottleneck for the commercial generation of transgenic cultivars. Thus, elucidating the molecular mechanism that underlies drought tolerance in sugarcane is mandatory for developing new cultivars with improved drought tolerance. Therefore, our group has dedicated efforts to understand the molecular basis of drought tolerance in sugarcane aiming to identify candidate target genes to improve sugarcane yield under conditions of low water availability. In a previous experiment (Oliveira, 2012), transcriptome analyses (microarray and RNA-seq) of two sugarcane genotypes contrasting in drought tolerance were performed to identify stress responsive genes.

Among several candidate genes, $S h D J$ was upregulated in response to drought. Therefore, we chose the ShDJ gene characterized its role in drought tolerance. The ShDJ full-length coding DNA sequence (CDS) was cloned and overexpressed in rice, a monocot model used in functional genomics (Tyagi and Mohanty, 2000). We investigated the performance of transgenic rice lines constitutively expressing the $S h D J$ gene under varying levels of water availability. Our results indicated that constitutive expression of the ShDJ gene improved drought tolerance in transgenic rice lines and exerted a positive impact on biomass accumulation, an important trait for agriculture. Then, we further investigated possible changes in cell wall components (cellulose, hemicellulose, and pectin) and lignin composition, as these elements affect the production of lignocellulosic bioethanol (Bottcher et al., 2013), also known as second-generation ethanol 
(E2G). Biochemical analyses revealed that ShDJ-overexpression modulated pectin and hemicellulose components, and improved saccharification efficiency. Together, our findings may represent a disruptive technology for the development of a sugarcane cultivar overexpressing ShDJ, which would be drought tolerant and show higher biomass production with enhanced saccharification for the sugar, E1G and E2G industries.

\section{MATERIALS AND METHODS}

\section{Sugarcane Dirigent-Jacalin Gene Identification and Expression Analyses}

In order to understand the mechanisms involved in the drought response of sugarcane plants, 'IACSP94-2094' (drought-tolerant) and 'IACSP97-7065' (drought-sensitive) sugarcane (Saccharum spp.) genotypes developed by "Programa Cana" (Instituto Agronômico, Ribeirão Preto, Brazil) were previously evaluated under irrigated and non-irrigated conditions both on field and greenhouse conditions (Oliveira, 2012). The field trial was carried out in Goianésia, Brazil $\left(15^{\circ} 13^{\prime} \mathrm{S} ; 48^{\circ} 56^{\prime} \mathrm{W}\right)$ during the dry season. Briefly, leaf samples (leaf +1 ) of first-cut plants were collected between 9:00 and 9:30 a.m. in irrigated (the irrigation was applied by linear sprinkler system) and non-irrigated areas at 42, 89, and 117 days after the last rainfall, when plants were 6, 7, and 9 months old respectively. The greenhouse trial was carried out in Campinas, Brazil $\left(22^{\circ} 52^{\prime} \mathrm{S} ; 47^{\circ} 44^{\prime} \mathrm{W}\right)$, and both genotypes were grown in the same tanks $\left(0.6 \mathrm{~m}^{3}\right)$ containing soil previously fertilized according to Van Raij et al. (1996). Leaf samples (leaf +1 ) from 6 months old plants were collected between 9:00 and 9:30 a.m. in irrigated and non-irrigated treatments at: 15 and 21 days after water withholding deficit and also after 9 days of soil rehydration for evaluating plant recovery. For more details about field and greenhouse trials, refer to Andrade et al. (2016). Leaf samples from both field and greenhouse experiments were subjected to microarray and RNA-seq assays, respectively (Oliveira, 2012). From these expression global analyses, ShDJ was chosen to be validated by real time quantitative polymerase chain reaction (RT-qPCR) in the present study.

Total RNA was extracted from leaves, according to Chang et al. (1993). Genomic DNA was removed using DNase I, following the manufacturer's instructions (Promega, Fitchburg, WI, United States). RNA concentration was determined using a spectrophotometer NanoDrop 2000 (Thermo Fisher Scientific, Wilmington, DE, United States), and RNA integrity was checked in $1.0 \%$ agarose gel electrophoresis stained with ethidium bromide $\left(1 \mu \mathrm{g} \mathrm{mL}^{-1}\right)$. Reverse transcription reaction was synthesized from $1 \mu \mathrm{g}$ of total RNA using the QuantiTect ${ }^{\circledR}$ Reverse Transcription Kit following the manufacturer's instructions (Qiagen, Foster City, CA, United States).

Real time quantitative polymerase chain reaction reactions were performed on the Applied Biosystems StepOnePlus System (Foster City, CA, United States). Briefly, a $10 \mu \mathrm{L}$ reaction mixture consisted of $5 \mu \mathrm{L}$ SYBR Green Super Mix (Applied Biosystems, Foster City, CA, United States), $3 \mu \mathrm{L}$ of diluted cDNA (1:30) with $0.2 \mu \mathrm{M}$ primers concentration, besides a negative control (without cDNA) included for each primer combinations. Expression was evaluated by the $2^{-\Delta \mathrm{Ct}}$ method $[n=3 \pm$ standard error (SE)], which represents the relative quantification of ShDJ expression in relation to the UBQ1 reference gene (Andrade et al., 2017), as shown in Supplementary Table 1.

\section{Alignments and Phylogenetic Analyses}

The ShDJ gene sequence (SUCEST Accession No. SCJLLR1103A10) was used as a bait for identifying its homologous using Basic Local Alignments Search Tools (Altschul et al., 1997) in different databases, such as the SUCEST database ${ }^{1}$, GenBank $\left(\mathrm{NCBI}^{2}\right)$, and Phytozome ${ }^{3}$ (Supplementary Table 2). Sugarcane assembled sequences (SAS) were retrieved using the tblastn tool with a cut-off of E-value $2 e^{-56}$, and a minimum SAS coverage rate in relation to the original protein sequence used as bait of at least $50 \%$. Homologous ShDJ protein sequences obtained from sugarcane hybrid (Sh), Sorghum bicolor $(\mathrm{Sb})$, maize $(\mathrm{Zm})$, rice (Os), Hordeum vulgare (Hv), Brachypodium distachyon (Bd), Triticum aestivum (Ta), and Arabidopsis thaliana (At) (Supplementary Table 2) were aligned the domain DJ proteins using ClustalW program (Thompson et al., 1994) based on Jaccard's index of similarity. Phylogenetic analyses was generated and visualized using Mega 6 (Tamura et al., 2013), with the maximum likelihood cluster analyses based on the JTT amino acid substitution matrix (Jones et al., 1992). Rates among sites were obtained using Gamma Distributed (with five discrete gamma categories). Trees were generated using BIONJ (Gascuel, 1997), a modified neighbor-joining algorithm, and each node was tested with 1,000 bootstrap replicates.

\section{Construction of the ShDJ Expression Cassette and Rice Transformation}

To construct the overexpression vector, the complete open reading frame (ORF) of $S h D J$ cDNA sequence was obtained using the SMARTer RACE cDNA Amplification Kit (Clontech, Mountain View, CA, United States), and the CDS was cloned into a pGEM-Teasy (Promega, Fitchburg, WI, United States). The binary vector $\mathrm{pHb} 7 \mathrm{~m} 24 \mathrm{GW}$, from the Functional Genomics unit of the Department of Plant Systems Biology (VIB-Ghent University), carrying the maize ubiquitin promoter ( $\mathrm{pEN}$ L4UBIL-R1) driving ShDJ expression, and the hygromycin phosphotransferase gene as a selectable marker (Karimi et al., 2007), was obtained by multi-recombination using the Gateway Recombination System ${ }^{\mathrm{TM}}$ (Invitrogen Life Technologies, United States), and transferred to Agrobacterium tumefaciens strain EHA105.

Embryogenic calli were obtained from mature seeds of Japonica rice (Oryza sativa L. 'Nipponbare'), and transgenic lines were produced as described by Toki et al. (2006), with modifications. Plants were regenerated on medium containing $30 \mathrm{mg} \mathrm{L}^{-1}$ hygromycin for selection and $20 \mathrm{mg} \mathrm{L}^{-1}$ Meropenem to prevent overgrow of $A$. tumefaciens. The progenies were obtained by self-pollination following the selection of seeds

\footnotetext{
${ }^{1}$ http://sucest-fun.org/

${ }^{2}$ http://www.ncbi.nlm.nih.gov/

${ }^{3}$ https://phytozome.jgi.doe.gov/
} 
through a germination test on hygromycin-containing media. Seeds of ShDJ lines were screened on $1 / 2$ MS medium supplemented with $50 \mathrm{mg} \mathrm{L}^{-1}$ hygromycin (incubation at $27^{\circ} \mathrm{C}$ for 7 days under a $16 \mathrm{~h}$ photoperiod) to obtain $\mathrm{T}_{1}$ and successive progenies for further analyses.

\section{Gene Expression Analyses of ShDJ Transgenic Lines}

Total RNA was isolated from rice tissues as described by Chang et al. (1993). To nullify any genomic DNA contamination, isolated RNA was treated with RQ1 RNase-Free DNase following the manufacturer's instructions (Promega, Fitchburg, WI, United States). RNA concentration was determined using a NanoDrop 2000 spectrophotometer (Thermo Fisher Scientific, Wilmington, DE, United States), and RNA integrity was checked in $1.0 \%$ agarose gel electrophoresis stained with ethidium bromide $\left(1 \mu \mathrm{g} \mathrm{mL}^{-1}\right)$. First-strand cDNA was synthesized from $1 \mu \mathrm{g}$ of total RNA with the GoScript ${ }^{\mathrm{TM}}$ Reverse Transcription System (Promega, Fitchburg, WI, United States), according to the manufacturer's instruction. RT-qPCR was carried out in the StepOnePlus System (Applied Biosystems, Foster City, CA, United States) using GoTaq ${ }^{\circledR} \mathrm{qPCR}$ Master Mix (Promega, Fitchburg, WI, United States).

Gene-specific primers of the cell wall and drought-stress responsive genes used in RT-qPCR analyses are listed in Supplementary Table 1. Analyses of transgene expression level ( $n=3 \pm$ standard error) were conducted using rice eukaryotic elongation factor- $1 \alpha$ gene (Accession No. AK061464) as endogenous control to normalize the cDNA variance between samples (Martins et al., 2018).

\section{Transgene Copy Number Estimation in ShDJ Lines}

To confirm the copy number of T-DNA inserted in the transgenic lines, genomic DNA from leaves was isolated using the cetyltrimethylammonium bromide (CTAB) method (Aljanabi et al., 1999). ShDJ copy number was evaluated in primary transformants $\left(\mathrm{T}_{0}\right)$ by PCR using Taqman ${ }^{\circledR}$ Assay technology (Applied Biosystems, Foster City, CA, United States). The hptII and sucrose phosphate synthase (SPS) primers and TaqMan probes were synthesized by Applied Biosystems (Foster City, CA, United States) and used in all analyses (Supplementary Table 1) (Ding et al., 2004). RT-qPCR and thermal profile reactions were performed as described by Martins et al. (2018) and the transgene copy number was determined as described by Mason et al. (2002) method.

\section{Transgenic Rice Plants Under Water Deficit Conditions}

Transgenic rice seedlings were transferred to pots $(5 \mathrm{~L}$ for $\mathrm{T}_{1}$; and $3 \mathrm{~L}$ for $\mathrm{T}_{4}$ plants) containing a mixture $(1: 1, \mathrm{v} / \mathrm{v})$ of soil and substrate (Carolina Soil, Santa Cruz do Sul, Brazil) and grown under greenhouse conditions in Ribeirão Preto, Brazil $\left(21^{\circ} 11^{\prime} \mathrm{S}, 47^{\circ} 48^{\prime} \mathrm{W}\right)$. Each pot contained one WT rice and one transgenic rice seedling, to ensure they were exposed to the same levels of water availability (Verslues et al., 2006). During the experimental period, the maximum photosynthetically active radiation (PPFD) and average air temperature were $1,567 \mu \mathrm{mol} \mathrm{m} \mathrm{m}^{-2} \mathrm{~s}^{-1}$ and $26.8 \pm 8.8^{\circ} \mathrm{C}$ for $\mathrm{T}_{1}$ plants, and $1,691 \mu \mathrm{mol} \mathrm{m}{ }^{-2} \mathrm{~s}^{-1}$ and $27.2 \pm 3.1^{\circ} \mathrm{C}$ for $\mathrm{T}_{4}$ plants. Those environmental conditions were monitored with a Watch Dog 1450 Micro Station (Spectrum Technologies, Aurora, IL, United States).

To evaluate drought tolerance at the whole-plant level, two treatments were imposed 45 days after sowing (DAS): the control condition ( $n=4 \pm$ standard error), in which plants were maintained well-watered through daily irrigation; and the water deficit condition, which was induced by water withholding. According to Hsiao et al. (1984), severe stress for rice plants is considered when there is visible leaf wilting. In fact, this occurred in two previous pilot experiments and we adopted leaf wilting as an index of stress level. The recovery capacity of plants previously exposed to severe stress was evaluated $24 \mathrm{~h}$ after rehydration. Then, four plants from each ShDJ line and WT plants were used to evaluate total dry mass and tillering. Pot weight was evaluated daily to monitor the water availability (Supplementary Figure 1).

To evaluate plant survival under greenhouse conditions, 1-month old $\mathrm{T}_{4}$ progeny seedlings were maintained in substrate (Carolina Soil, Santa Cruz do Sul, Brazil) under well-watered. The water was withheld from for 5 days, which was sufficient to cause leaf wilting in transgenic rice overexpressing ShDJ. Then, plants were re-watered for two days, recovery was evaluated, and survival rates were estimated based on the percentage of survival in relation to all plants tested.

\section{Cell Wall Composition and Saccharification Analyses}

Cell wall analyses were carried out in plants maintained under well-watered and water deficit conditions. Analyses were performed in shoots (stem and leaves) of $\mathrm{T}_{4}$ transgenic lines and WT plants, with four biological replicates each. Cell wall polysaccharides were evaluated as described by Chen et al. (2002) and the soluble and insoluble lignin contents (Klason's Methods) were determined following the Tappi protocol UM-250 (TAPPI, 1985). The saccharification ratio was measured as described by methodology of Brown and Torget (1996), with modifications as described by Martins et al. (2018).

\section{Statistical Analyses}

The experimental design was randomized in a $2 \times 2$ factorial scheme, with variation in terms of ShDJ (transgenic lines and WT plants) and water regimes (well-watered and water deficit). Data were subjected to analyses of variance (ANOVA) and when statistical significance was detected, the mean values were compared using a t-test $(P<0.05)$ with SAS statistical software (version 9.2; SAS Institute, Inc., Cary, NC, United States). 


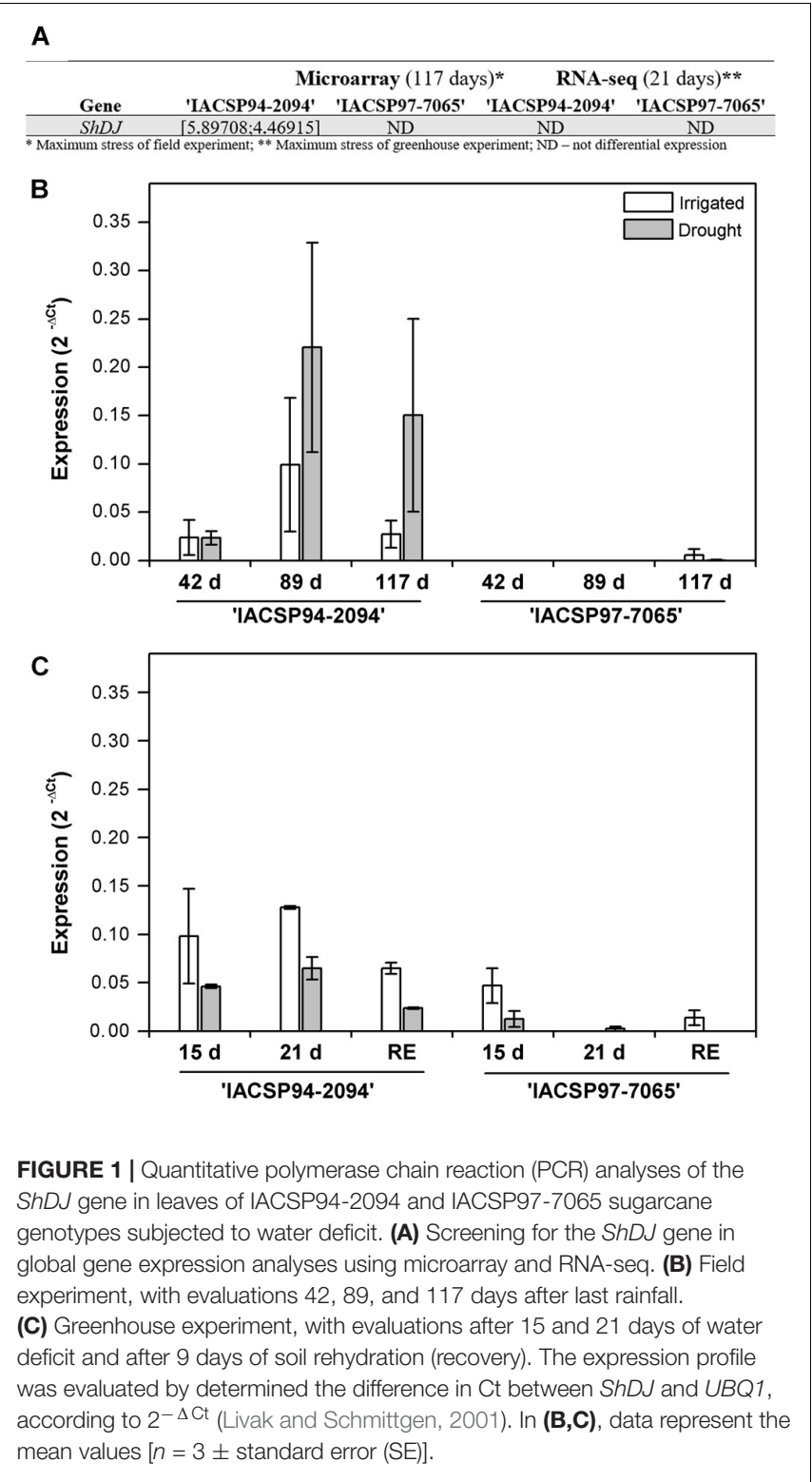

\section{RESULTS}

\section{ShDJ Gene Expression in Sugarcane Genotypes With Contrasting Drought Tolerance}

The global expression analyses of 'IACSP94-2094' (droughttolerant) and 'IACSP97-7065' (drought-sensitive) sugarcane (Saccharum spp.) genotypes were performed using microarray and RNA-seq assays in leaves provided from field and greenhouse experiments, respectively (Oliveira, 2012). Further details about the experiments and methodologies are described in Andrade et al. (2016).

Among several differentially expressed candidate genes, the expression of dirigent-jacalin gene (SUCEST accession no.
SCJLLR1103A10), here named ShDJ (Saccharum hybrid DirigentJacalin) increased when the tolerant genotype was subjected to water deficit under field conditions (Figure 1A). In order to evaluate $S h D J$ expression, RT-qPCR assays were performed for each genotype, using the same leaf tissues (leaf +1 , i.e., the first fully expanded leaf with visible ligule) used for the microarray and RNA-seq assays and sampled in both field $(42,89$, and 117 days after the last rainfall) and greenhouse (15 and 21 days of water deficit and after 9 days of recovery) experiments.

Under field conditions, ShDJ transcripts were not detected 42 and 89 days after the last rainfall in 'IACSP97-7065' (Figure 1B). Conversely, $S h D J$ transcripts were detected at all time points in 'IACSP94-2094,' with drought-stressed plants presenting higher transcript levels than irrigated plants after 89 and 117 days of water deficit conditions (Figure 1B). Under greenhouse conditions, ShDJ expression responded to drought in the 'IACSP94-2094' genotype, with lower transcript abundance under drought conditions compared with irrigated conditions. In 'IACSP97-7065', the ShDJ transcript was not detected after 21 days of water deficit and after rehydration (Figure 1C). Based on these results, the role of the ShDJ gene on drought tolerance was further investigated by sequence and phylogenetic analyses, followed by cloning and rice heterologous overexpression.

\section{Phylogenetic Analyses of ShDJ}

A total of 46 annotated amino acid sequences homologous to ShDJ were obtained from various plant species (Supplementary Table 2) and used to construct a phylogenetic tree (Figure 2), aiming to investigate the evolutionary history of DJ proteins. Two SAS from the SUCEST database were identified as a chimeric DJ protein, and the sequences were named DIR4/JRL (SCJLLR1103A10, corresponding to ShDJ) and DIR8/JRL (SCCCRT3002G10) according to Nobile et al. (2017). The phylogenetic tree presented three major groups composed of DJ and Jacalin sequences (Figure 2). The DJ proteins comprised the major group I exclusive for monocot plants, while group II and group III were formed by proteins with a jacalin domain from rice and Arabidopsis, respectively (Figure 2). Two JRL sugarcane sequences (SCJLRT1020A04-JRL and SCBGST31051112-JRL) were positioned between group II and group III (Figure 2).

The sequence similarity search revealed several proteins with high identity to ShDJ. The phylogenetic tree showed that the ShDJ protein was close to rice (Os12g12720-DIR/JRL, OsEAY82651-DIR/JRL, Os12g14440-DIR/JRL, Os12g09720Dir/JRL, Os12g09700-DIR/JRL), Hordeum vulgare (HvDIR/JRL) and sorghum (Sb005G183600-DIR/JRL) (Monocot JRL, Figure 2). ShDJ was closest to sorghum (Sb005G183600), showing high confidence level (100\% bootstrap). According to blast2, ShDJ, and Sb005G183600 shared 85\% identity.

\section{Isolation and Characterization of ShDJ}

The ShDJ gene sequence in the SUCEST database is incomplete; then the full-length sequence was revealed by using SMARTer ${ }^{\mathrm{TM}}$ RACE cDNA Amplification Kit (Clontech, Mountain View, CA, United States). The CDS of the ShDJ gene was successfully amplified from the $5^{\prime}$ and $3^{\prime}$ RACE libraries of 'IACSP942094 ' leaves. The cloned ShDJ full-length sequences revealed two 


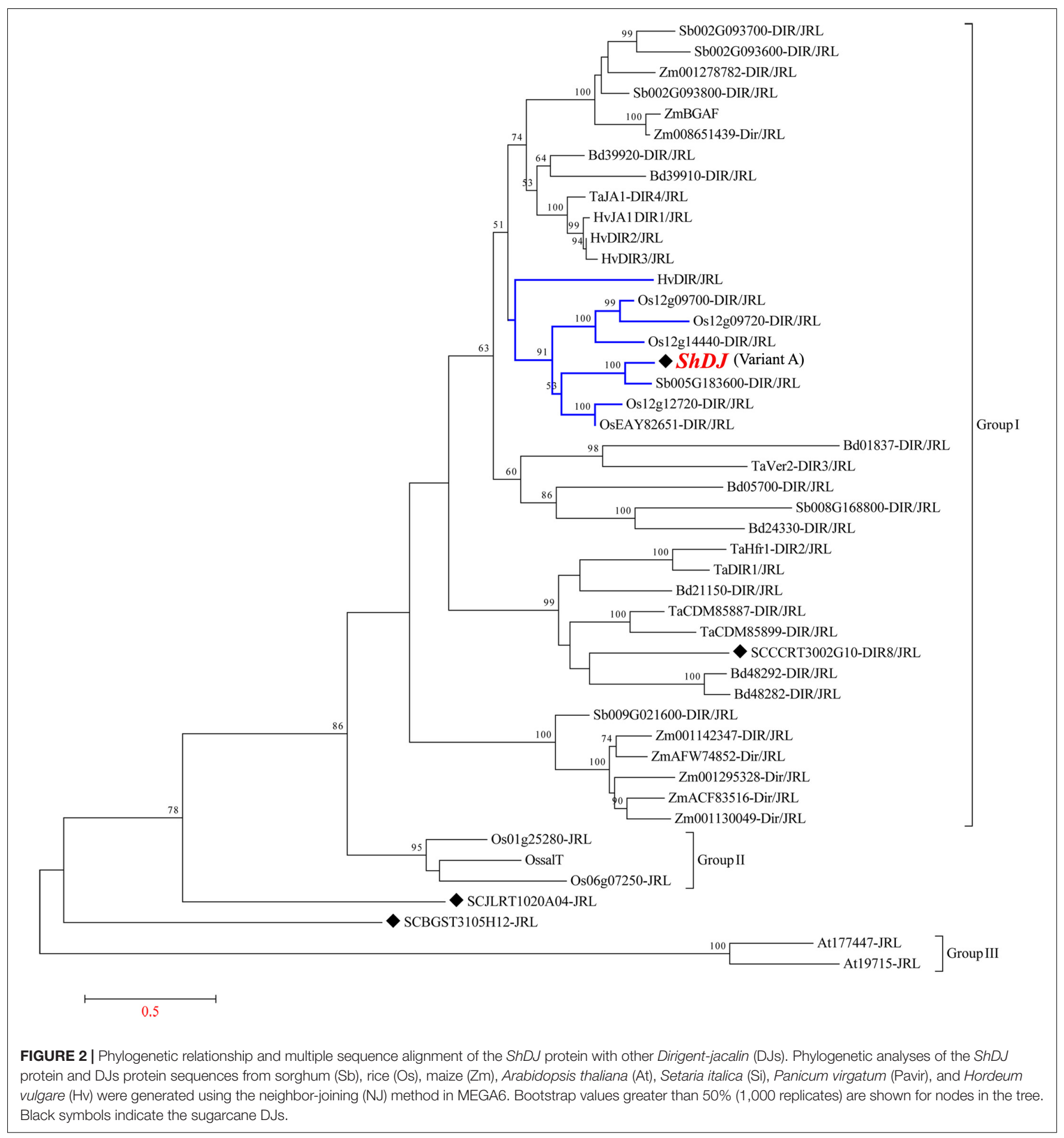

probable allelic variants A and B (Supplementary Figure 2). Variant B (MK000561) presented four additional nucleotides compared with to variant A (MK000560), thereby changing the ORF, to encode a truncated protein (Supplementary Figure 2). Therefore, variant A was used for vector construction and for functional genomic analyses. The isolated sequence exhibited a $924 \mathrm{bp}$ ORF encoding a polypeptide of 308 amino acids with a predicted molecular mass of $76.09 \mathrm{kD}$ and isoelectric point (pI) of 5.07 calculated with the ExPASy compute $\mathrm{pI} / \mathrm{Mw}$ tool ${ }^{4}$. The 308 amino acids encode a dirigent (amino acids 29-148) and a jacalin (amino acids 175-306) domain according to a BLAST protein-protein search of $\mathrm{Pfam}^{5}$.

\footnotetext{
${ }^{4}$ https://web.expasy.org/compute_pi/

${ }^{5}$ https://pfam.xfam.org/
} 


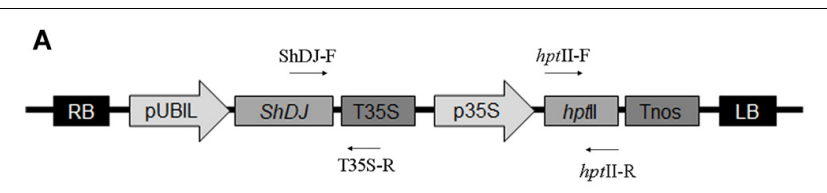

B

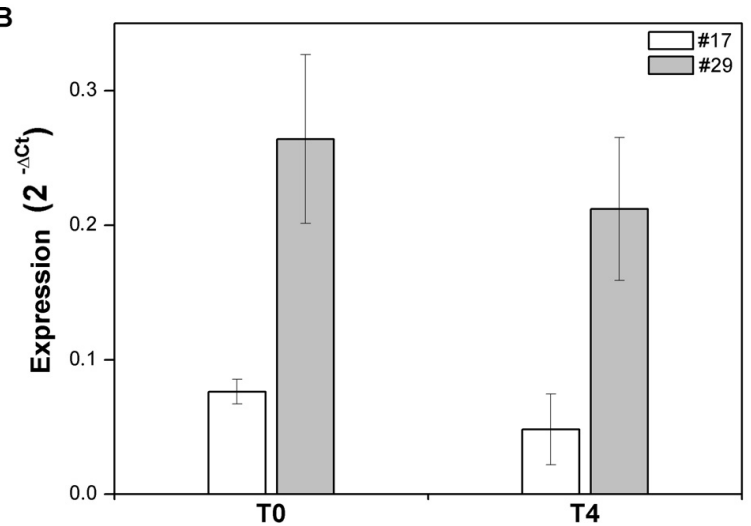

FIGURE 3 | Molecular characterization of ShDJ lines. (A) Schematic representation of the T-DNA region of the binary vector pUBIL::ShDJ. RB, right border; LB, left border; pUBIL, maize ubiquitin promoter; Tnos, nopaline synthase terminator; p35S, 35S promoter; hptll, hygromycin phosphotransferase gene (selectable marker); T35S, 35S terminator. (B) Analyses of $S h D J$ expression in rice plants of $T_{0}$ and $T_{4}$ generations. Abundance of the ShDJ transcripts in lines \#17 and \#29 was evaluated by real time quantitative polymerase chain reaction (RT-qPCR) analyses ( $n=3 \pm$ standard error) using gene-specific primers for ShDJ. Analyses used the $2^{-\Delta C t}$ method (Livak and Schmittgen, 2001), in which $\Delta$ Ct represents the relative quantification of a target gene and a reference gene (elF-1 $\alpha)$.

\section{Overexpression of the ShDJ Gene Increases the Drought Tolerance of Rice Plants}

To investigate the role of $S h D J$ in drought tolerance, a $S h D J$ overexpression vector was constructed under control of the maize ubiquitin promoter and used for rice transformation (Oryza sativa L.) (Figure $\mathbf{3 A}$ ). Thirty independent lines were produced, hereafter called rice ShDJ lines, and confirmed as positive transformants by conventional PCR in $\mathrm{T}_{0}$ plants (data not shown). The ShDJ lines grew to maturity for setting seeds, and no morphological alterations were observed under normal growth conditions. Variation in the transgene expression of ShDJ lines was evaluated by RT-qPCR, ranging from 0.003 to 0.617 (Supplementary Figure 3). Among ShDJ lines, line \#24 showed the highest $S h D J$ expression and line \#5 showed the lowest expression, whereas no ShDJ expression was detected in WT plants (Supplementary Figure 3), as expected.

Analyses of transgene expression were followed by evaluation of copy number as described by Mason et al. (2002) using TaqMan methodology. Twelve ShDJ lines showing differential expression of the ShDJ transgene (high, medium, and lower) were chosen, and the transgene copy number integrated into the genome ranged from 1 to 4 (Supplementary Figure 3). According to those results, $\mathrm{T}_{1}$ progeny from five independent transgenic lines (\#1, \#8, \#17, \#24, and \#29) exhibiting different expression levels, but carrying one transgene copy were selected to evaluate the role of ShDJ under water deficit conditions. In a preliminary experiment, five $S h D J$ lines of $\mathrm{T}_{1}$ progeny were evaluated for drought tolerance under greenhouse conditions. Following this initial screening, transgenic lines \#17 and \#29 were further investigated considering $\mathrm{T}_{4}$ progeny (Figure $3 \mathbf{B}$ ). Lines \#17 and \#29 were chosen due to their drought tolerance and biomass accumulation, and represent the greatest contrast to WT plants.

Leaf wilting was observed after 12 and 8 days of water deficit in $\mathrm{T}_{1}$ and $\mathrm{T}_{4}$ progenies, respectively. When evaluating $\mathrm{T}_{1}$ progeny, line \#17 exhibited higher biomass and tillering compared with the WT plants under water deficit conditions, while line \#29 exhibited higher vigor than WT plants under both water regimes (Figures 4A,B). In $\mathrm{T}_{4}$ progeny, line \#29 showed higher biomass and line \#17 presented higher tillering compared with WT plants under water deficit conditions (Figures 4C,D). In general, tillering was improved in ShDJ transgenic line \#17 under water deficit conditions, regardless of progeny. Among the $\mathrm{T}_{1}$ progeny, line \#29 showed a large increase in biomass under both wellwatered and water deficit conditions (Figure 4B). No differences were found in the seed size of transgenic lines under varying levels of water availability (Supplementary Figure 4).

To investigate the role of $S h D J$ in plant survival under drought, water was withheld from rice seedlings for 5 days. The survival rate (\%) was determined 2 days after re-watering. The survival rate of the transgenic lines was higher than that of the WT plants (Figure 5). Notably, none of the WT plants survived under water deficit conditions $(0 \%)$, while only one transgenic plant (out of 68), line \#17 failed (98,5\%), and all plants of line \#29 survived (100\%) following rehydration. These results clearly revealed the role of the $S h D J$ gene on the drought tolerance of transgenic plants.

In addition, $S h D J$-overexpression was evaluated for salinity tolerance. Although a recent report showed that drought and salinity tolerance share the same complex regulatory processes involved in cellular homeostasis (for review, see Golldack et al., 2014), no differences were observed in ShDJ transgenic lines when compared with WT plants under salt stress (Supplementary Figure 5). All the experiments have been adhered the standard biosecurity and institutional safety procedures, following requirements and biosafety procedures of National Technical Commission on Biosafety (CTNBio) to GMOs manipulation biosafety level 1 .

\section{ShDJ-Overexpression in Rice Causes Changes in the Cell Wall Composition}

Besides increasing drought tolerance, the overexpression of ShDJ was investigated considering possible modifications in cell wall composition, such as lignin and polysaccharides. Cell wall composition was evaluated in T4 progeny and WT plants, considering the entire plant shoots. ShDJ and WT plants showed different ranges of pectin, hemicelluloses, cellulose, and total lignin contents. Under well-watered conditions, lines \#17 and \#29 presented a significant decrease in pectin and hemicellulose compared with WT plants, with reductions ranging 

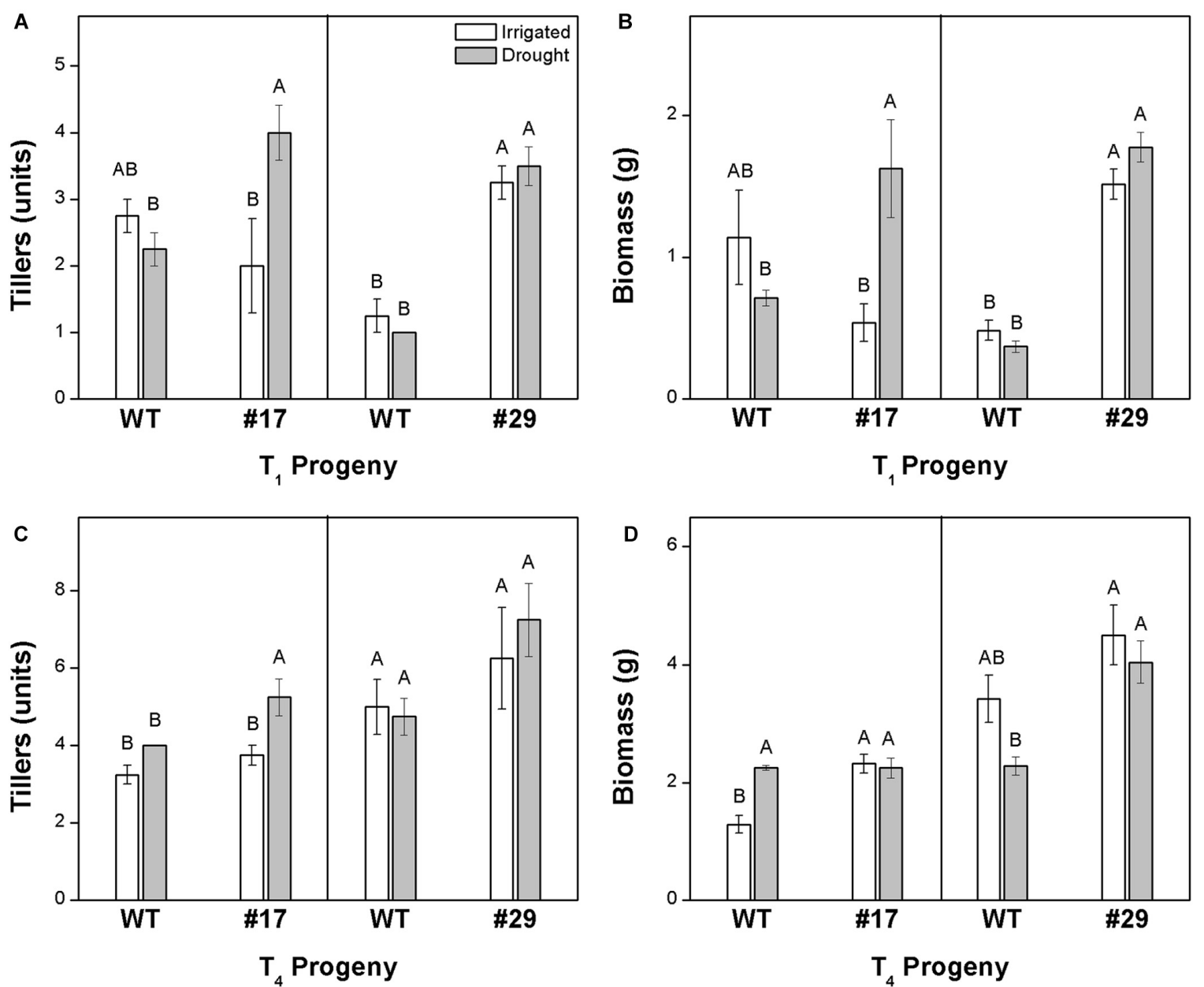

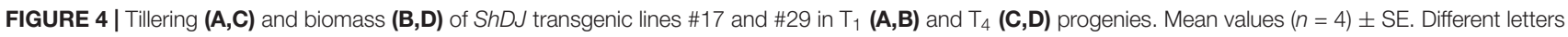
indicate significant differences between plants and water conditions ( $t$-test, $P<0.05)$.

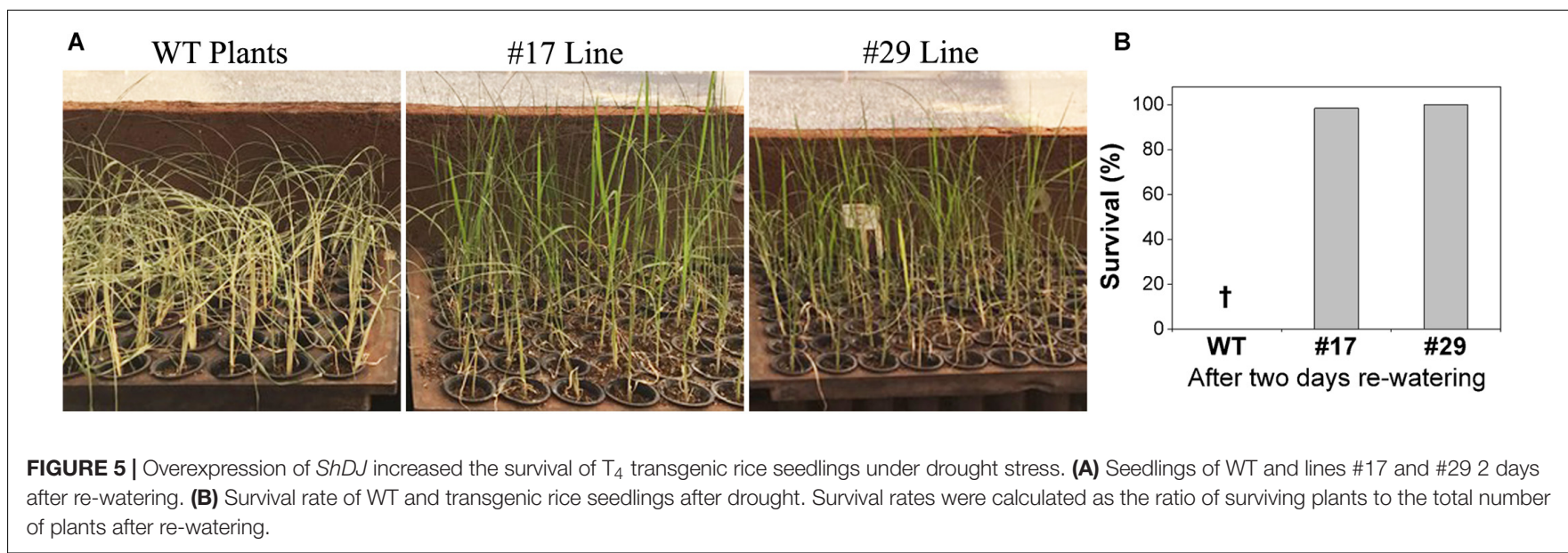

from $\sim 18-30$ to $\sim 13-25 \%$, respectively (Figures 6A-D). Under water deficit conditions, no significant difference in pectin was observed in line \#17, whereas a decrease in hemicellulose content was observed in both transgenic lines compared with WT
(Figures 6A-D). ShDJ overexpression did not affect cellulose content in line \#17 under both water regimes, whereas the cellulose content of line \#29 was lower $(-14 \%)$ than that in WT plants under water deficit conditions (Figures 6E,F). Regarding 


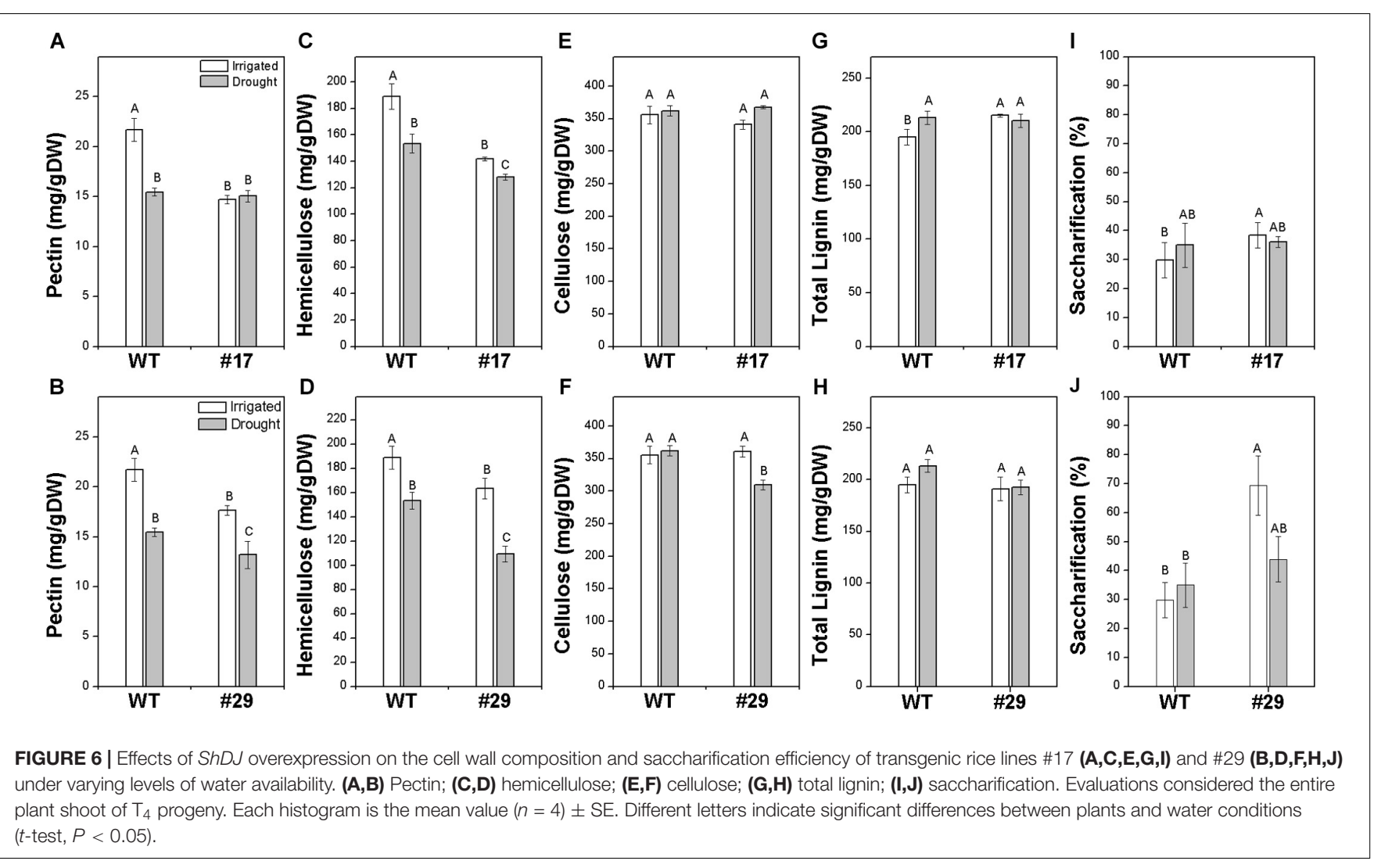

lignin, there was a significant increase in line \#17 compared with WT plants (Figure 6G). Conversely, ShDJ overexpression in line \#29 did not affect total lignin under both water regimes (Figure $\mathbf{6 H}$ ). We also found significant increases in saccharification efficiency in lines \#17 and \#29, ranging from $28 \%$ (line \#17) to $132 \%$ (line \#29) compared with WT plants under well-watered conditions (Figures 6I,J).

\section{Expression Analyses of Secondary Cell Wall and Drought-Stress Responsive Genes in ShDJ Transgenic Lines}

To investigate the contribution of constitutive ShDJ expression in transgenic rice lines, the expression pattern of genes involved in the regulation of the secondary cell wall (OsMYB58/63 and OsNST1/2) and water deficit response (OsP5CS, OsLea3, OsGRAS23, and OsbZIP23) was assessed. Gene expression pattern of leaves and stems of $\mathrm{T}_{4}$ plants were compared under wellwatered conditions.

The expression of OsMYB58/63 (Ambavaram et al., 2011; Noda et al., 2015) and OsNST1/2 (Ambavaram et al., 2011) were significantly increased in the leaves of line \#17 (11- and 1.3-fold increases, respectively) compared with WT plants (Figure 7A). In line \#29, OsMYB58/63 expression was down-regulated in leaves (2.3-fold) and stems (24-fold), while OsNST1/2 expression was reduced only in stems (1.5-fold) (Figure $7 \mathbf{B})$.

There was a significant decrease in OsP5CS (Zhang and Chen, 2017) expression in leaves of line \#17 compared with WT plants (1.5-fold), while expression was up-regulated (2.2-fold) in stems of line \#29 (Figure 7). OsLea3 (Zhang and Chen, 2017) expression was up-regulated in stems, with lines \#17 and \#29 showing 3.4- and 31-fold higher expression compared with WT plants (Figure 7). Decreased expression of OsLea3 was observed in leaves of line \#17 (Figure 7A). Transcription factors related to drought stress via ABA-independent (OsGRAS23; Xu et al., 2015) and ABA-dependent (OsbZIP23; Xiang et al., 2008) pathways were also evaluated and found to present a similar expression profile. While the transcript abundance of OsGRAS23 was clearly decreased in leaves of lines \#17 (3.9-fold repression) and \#29 (2.5fold repression) compared with WT, it was increased (3-fold) in stems of line \#29 (Figure 7). OsbZIP23 expression was upregulated in stems of lines \#17 (1.7-fold) and \#29 (6.4-fold) and down-regulated (5.61-fold) in leaves of line \#17 (Figure 7).

\section{DISCUSSION}

In the present study, expression of the ShDJ gene was systematically investigated in sugarcane genotypes with contrasting levels of drought tolerance and characterized in drought stress through the heterologous overexpression of $S h D J$ in rice. Rice (Oryza sativa) is widely used as a model plant for functional analyses of monocots. Therefore, we used rice for functional analyses of sugarcane genes as it is a monocot plant evolutionarily close to sugarcane and has well-established transformation protocols. Furthermore, rice is 


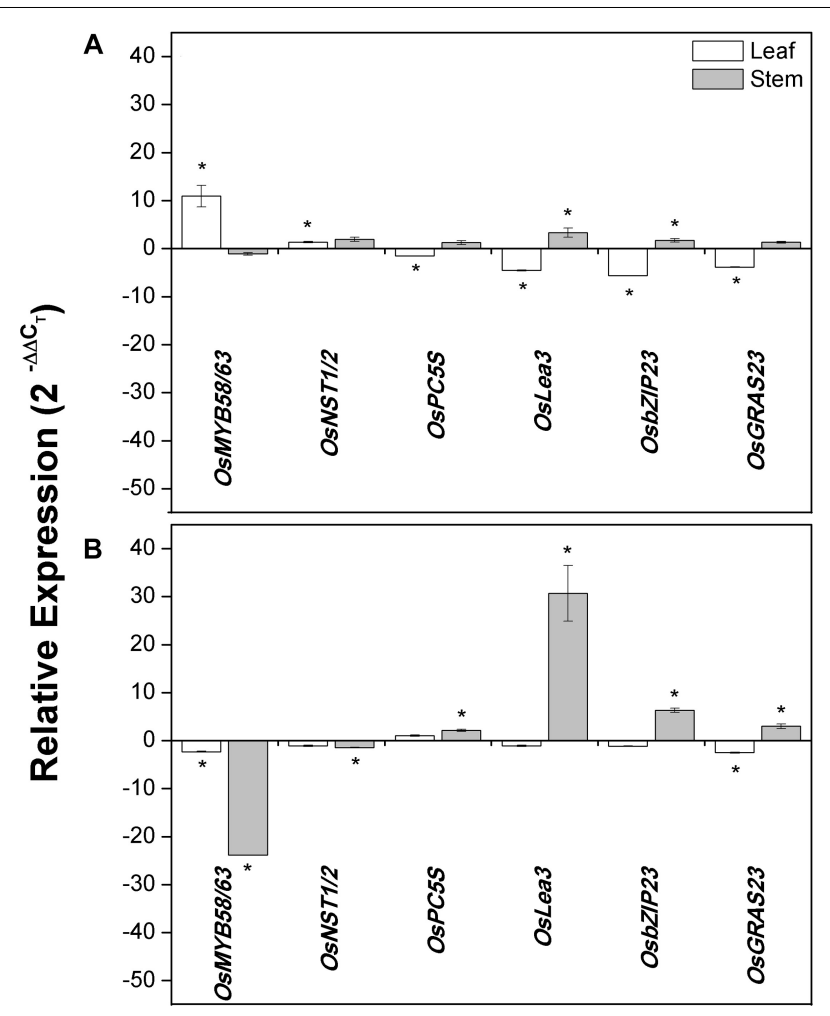

FIGURE 7 | ShDJ modified the expression of cell wall and drought-related genes in leaves and stems of transgenic rice lines (A) \#17 and (B) \#29. Expression profiles of OsMYB58/63, OsNST1/2, OsP5CS, OsLea3, OsbZIP23, and OsGRAS23 genes observed by RT-qPCR analyses in $\mathrm{T}_{4}$ plants were maintained under irrigated conditions. Expression in transgenic lines is relative to that in WT plants using the $2^{-\Delta \Delta \mathrm{Ct}}$ method (Livak and Schmittgen, 2001). Data are mean values $(n=3) \pm$ SE, and asterisks on the top of each bar indicate significant differential expression between lines and WT as determined using REST○) software (5\% significance).

a diploid species with a small genome (about 7-8 fold smaller than sugarcane genome), and with a short life cycle (up to three generations per year). Our recent results of sugarcane genes overexpressed/silenced in rice have shown linearity with those obtained from the overexpression/silencing in sugarcane (proof of concept - data not published). Indeed, rice is a good model for functional analyses of sugarcane genes evolved in drought stress, although we need to validate $S h D J$ in sugarcane.

Although genes encoding DJ proteins are widely present in monocot plants (Schutter and Van Damme, 2015), their biological functions are still poorly understood. The sugarcane genome contains at least four DJ groups comprising seven nonredundant sequences (Nobile et al., 2017), and ShDJ responded strongly to drought stress in 'IACSP94-2094, a droughttolerant genotype (Figure 1). Herein, RT-qPCR results validated transcriptome data for the $S h D J$ gene during drought stress under both field and greenhouse conditions.

Previous studies with proteins containing the dirigent-jacalin domain have demonstrated the involvement of this domain in pathogen resistance (Williams et al., 2002; Subramanyam et al., 2006; Ma et al., 2010; Song et al., 2014). Based on a search of
EST and microarray databases, only two studies in wheat have reported the responsiveness of DJ genes to drought stress (Song et al., 2014; Kumar et al., 2018). Song et al. (2014) showed that the expression of DJ genes was induced in response to PEG treatment, including TaJRL6 (identified in the phylogenetic tree as TaDIR1/JRL) present in group I (Figure 2). Based on their results, those authors suggested that JRL proteins seem to play an important role in plant adaptation under stressful conditions. In addition, Kumar et al. (2018) identified DJ genes, including Ta.188.1.S1_at (TaDIR1/JRL), using a microarray database, which were strongly induced under drought in drought-tolerant wheat genotype. Although JRL wheat proteins in these studies fall within group I of the DJ proteins, the probably orthologous groups are not evident among JRL genes. According to Walley and Dehesh (2010) and Xiao et al. (2013), biotic and abiotic stress pathways in plants are regulated by cross-talk between signaling networks. Therefore, DJ genes are inducible by both biotic and abiotic stresses, suggesting multiple roles of DJ genes in plants.

\section{ShDJ-Overexpression in Rice Promotes Drought Tolerance, Biomass Accumulation, and Improves Saccharification}

In this study, the role of the ShDJ gene in the water deficit response was characterized for the first time. Transgenic rice lines overexpressing the $S h D J$ gene were generated and phenotyped in response to water deficit stress under greenhouse conditions. Large differences in total biomass production (tiller number and total dry mass) were found between $\operatorname{ShDJ}$ lines and WT plants in both generations evaluated (Figure 4). Under drought, ShDJ lines maintained growth and development, resulting in higher biomass in lines \#17 and \#29, while a significant reduction in total dry mass occurred in WT plants (Figure 4). In contrast, the survival ratio test, revealed that the $S h D J$ lines showed strong tolerance to water deficit stress (Figure 5). These results strongly suggest that ShDJ plays a role in drought tolerance as well as in the growth and development of transgenic plants. The role in the growth and development of rice plants were suggested by Jiang et al. (2007). The authors evaluated the OsJAC1 gene promoter fused to the GUS reporter gene (pOsJAC1::GUS) and presents a constitutive gene expression in rice. However, when the OsJAC1 gene was driven by the maize constitutive promoter (Ubi::OsJAC1), the plants showed a reduction in coleoptile and stem elongation (Jiang et al., 2007). Similarly to our study, Ambavaram et al. (2014) observed that overexpression of the transcription factor HYR in rice resulted in an increase in grain yield and biomass accumulation, regardless of water availability. Likewise, Karaba et al. (2007) showed that constitutive expression of the HARDY Arabidopsis gene in rice, improved drought tolerance and increased biomass production. Recently, Bi et al. (2018) demonstrated that the overexpression of Arabidopsis SHN1 in wheat increased biomass production under drought stress conditions compared with WT plants. Therefore, a series of complex traits relevant to biomass or yield, such as survival rate, tillering, and dry mass have been used to evaluate the 
drought tolerance (Fang and Xiong, 2015). In fact, these traits are important criteria for phenotyping drought stress tolerance in crop breeding (Mitra, 2001).

To investigate how ShDJ would affect cell wall composition and saccharification efficiency, rice shoots of T4 progeny were examined. Biochemical analyses were also performed to elucidate the contribution of $S h D J$-overexpression to biomass saccharification, since the recalcitrance of cell walls to hydrolysis represents the major bottleneck for the E2G industry (Himmel et al., 2007). Under well-watered conditions, there was a significant reduction in pectin and hemicellulose in both transgenic lines compared with WT plants, whereas the cellulose content was unchanged under well-watered conditions (Figure 6). Under drought, there was a decrease in hemicellulose content in line \#17 and we observed a significant reduction in pectin, hemicellulose, and cellulose content in line \#29 (Figure 6). The same response to drought has been reported in wheat coleoptile (Wakabayashi et al., 1997), squash hypocotyls (Sakurai et al., 1987a,b), maize leaves (Acevedo et al., 1971), grape leaves (Sweet et al., 1990), corn stover, mixed grasses, and Miscanthus (Emerson et al., 2014). In those studies, drought had a negative impact on growth, and therefore on total biomass yield. Similarly, Lionetti et al. (2010) showed reduced polysaccharide content due to genetic modification of the cell wall inhibited plant growth. However, in our study, modulation of cell wall did not adversely affect the growth of transgenic lines, as they displayed normal plant phenotypes and even increases in biomass production (Figure 6).

Pectin and hemicellulose link cellulose and lignin, and this interaction has a major role in cell wall recalcitrance (Himmel and Bayer, 2009). Changes in cell wall polysaccharides may cause cell wall loosening (Thompson, 2005), and this loosening phenomenon, as proposed by Moore et al. (2008), is related to increases in cell wall elasticity (Gall et al., 2015), promoting polysaccharides accessibility and increasing biomass solubilization (Phitsuwan et al., 2013). Based on our results, the reduction of pectin and hemicellulose content in ShDJ lines compared with WT plants suggests less interaction between cell wall polysaccharides and a significant improvement in saccharification efficiency (Figure 6). Herein, we provide strong evidence that modifications in cell wall composition affect biomass recalcitrance, thus increasing saccharification. This may due to efficient enzymatic action, reducing interactions among pectin, hemicellulose, and lignocellulose components (Himmel et al., 2007; Scheller and Ulvskov, 2010). Removal of hemicellulose (Qing et al., 2010; Shin et al., 2010) and pectin (Lionetti et al., 2010; Chen and Peng, 2013; Biswal et al., 2014) from cell wall enhances saccharification. Downregulation of the GAUT12.1 gene (hemicellulose biosynthesis) in Populus deltoides by RNAi led to a reduction in recalcitrance due to decreases in hemicellulose and pectin contents, while lignin content was unchanged with a significant increase in plant growth (Biswal et al., 2015). Our results suggest that $S h D J$ acts by altering pectin and hemicellulose metabolism and support our hypothesis that overexpression of $S h D J$ increases drought tolerance and causes cell wall modifications, with benefits for plant growth saccharification in transgenic lines.

\section{Expression Profiles of Genes Related to Cell Wall Composition and Water Deficit Response}

Several studies have shown that changes in gene expression and regulatory genes (transcription factors) are involved in the activation of drought response and tolerance (Bartels and Sunkar, 2005). As ShDJ-overexpression could have affected many genes, we examined the molecular mechanisms modified in transgenic lines under well-watered conditions, considering genes involved in cell wall biosynthesis and water deficit tolerance.

Transcription factors OsMYB58/63 (Ambavaram et al., 2011; Noda et al., 2015) and OsNST1/2 (Ambavaram et al., 2011) regulate transcription of secondary cell wall genes. The present study evaluated OsMYB58/63 and OsNST1/2 genes to confirm that $S h D J$-overexpression affected the expression of cell wall genes in transgenic lines. In addition, Zhou et al. (2009) described MYB58 and MYB63 as transcriptional activators of the lignin biosynthetic pathway during secondary cell wall formation in Arabidopsis. However, we observed a contrasting expression profile of both genes in the transgenic lines evaluated. Expression of cell wall genes was induced in leaves of line $\# 17$, which was consistent with the higher lignin content in this line compared with WT plants (Figure 7). Conversely, the reduced expression of genes did not alter lignin content in line \#29 (Figure 7). A reduction in expression was observed by Ambavaram et al. (2011), and AtSHN-overexpression in rice directly repressed OsMYB58/63 and OsNST1/2 in leaves and stems, resulting in a large reduction in lignin content. Recently, Martins et al. (2018) demonstrated that the overexpression of sugarcane ShSHN1 in rice repressed OsMYB58/63 and OsNST1/2 in leaves and tillers followed by a decrease in lignin content in the transgenic lines and improvement of saccharification efficiency. Interestingly, ShSHN1 rice transgenic lines showed an increase in biomass production when compared with WT plants. Altogether, those results support the conclusion that ShDJ modulates the expression of OsMYB58/63 and OsNST1/2 genes related to cell wall formation. However, the relation between expression and cell wall components needs to be further studied and understood to uncover the underlying processes leading to biomass accumulation and how ShDJ affects them.

To date, various signaling pathways have been reported to be involved in drought tolerance in rice, including responsive genes and transcription factors. Earlier reports showed that activation of these genes improved drought tolerance (Xiao et al., 2007; Xiang et al., 2008; Xu et al., 2015; Lou et al., 2017; Zhang and Chen, 2017). LEA and P5CS proteins have crucial roles in osmotic adjustment in many plants, protecting them from damage caused by environmental stresses, such as drought (for review, see Fang and Xiong, 2015). Conversely, transcription factors play important roles in the transcriptional regulation of stress-related genes (Shinozaki et al., 2003).

In the present report, we found that ShDJ-overexpression upregulated the expression of drought-related genes and 
transcription factors in rice stems. OsP5CS and OsLea3 showed a similar expression profile, with increased expression levels observed in stems and decreased expressed in leaves in both transgenic lines compared with WT plants (Figure 7). According to Zhang and Chen (2017), the overexpression of OsNRRB activated the expression of OsLea3 and OsP5CS, while the expression of OsbZIP23 was repressed in leaves of wellwatered plants, as reported herein (Figure 7). Xu et al. (2015) observed that expression of the transcription factor OsGRAS23 was induced by drought stress, and showed that OsGRAS23overexpression is involved in abiotic stress responses, plant growth, development, and phytohormone signal transduction (e.g., JA) in rice. In addition, transgenic rice overexpressing OsLEA3 (Xiao et al., 2007) and OsbZIP23 (Xiang et al., 2008) presented a significant improvement in drought tolerance. In contrast, OsSAPK2-silenced plants, there were no differences in the expression levels of OsLea3, OsP5CS, and OsbZIP23 in leaves as compared with WT plants under well-watered conditions (Lou et al., 2017). Additionally, the overexpression of ShDJ increased the expression of OsbZIP23 and OsGRAS23 transcription factors in stems, revealing changes in ABA-dependent and ABAindependent signaling pathways, respectively. This suggests that drought tolerance can be genetically regulated by both hormonal pathways. Therefore, our results indicated that overexpression of the $S h D J$ gene in rice may impact the steadystate of transcription of stress-response genes, which may improve drought tolerance and promote changes in secondary cell walls.

\section{CONCLUSION}

In this study, we revealed that overexpression of ShDJ gene contributed to drought tolerance, maintaining plant growth and development of transgenic lines under conditions of low water availability. The ShDJ gene proved to be a good candidate for genetic transformation of plants to improve drought tolerance, using only one gene as a target. While further experimentation is needed under field conditions, our results highlight an interesting pathway for enhancing productivity within a sustainable context, where water is a limiting factor. Given that $S h D J$-overexpression promotes improvement in saccharification efficiency in rice, our findings are of special interest for bioenergy production using sugarcane. The development of new sugarcane cultivars focused on first (E1G) and second-generation (E2G) ethanol, and on the

\section{REFERENCES}

Acevedo, D., Hsiao, T. C., and Henderson, D. W. (1971). Immediate and subsequent growth responses of maize leaves to changes in water status. Plant Physiol. 48, 631-636. doi: 10.1104/pp.48.5.631

Aljanabi, S. M., Forget, L., and Dookun, A. (1999). An improved and rapid protocol for the isolation of polysaccharide- and polyphenol-free sugarcane DNA. Plant Mol. Biol. Rep. 17:281. doi: 10.1023/A:10076929 29505 co-generation of energy, should promote environmental and economic benefits, increasing crop yield per area planted.

\section{AUTHOR CONTRIBUTIONS}

JFCON, AF, RVR, and SC performed field and greenhouse sugarcane experiments. LMA, JFCON, PMN, RFP-J, CF, and MSB conducted global gene expression data analyses and RTqPCR assays. LMA, TRB, JS, and MHSG performed the cloning and vector construction for plant transformation. LMA, PERM, SDC, and RVR performed the drought assays with transgenic lines. JPPL and PM conducted the cell wall assays. LMA and DP performed statistical analyses. LMA and SC wrote the manuscript. PMN, MSB, and RVR provided intellectual input and revised the manuscript. All authors read and approved the final manuscript.

\section{FUNDING}

We acknowledge funding for this work from the "Conselho Nacional de Desenvolvimento Científico e Tecnológico" (CNPq, Brazil - 552381/2007-1) and the São Paulo Research Foundation (FAPESP, Brazil - 2011/50661-8, 2008/57495-3, and 2017/24420-0). The authors also acknowledge the fellowships and scholarships granted by CNPq (LMA, RFP-J, PERM, PM, and RVR), "Coordenação de Aperfeiçoamento de Pessoal de Nível Superior" - CAPES (APBM), and FAPESP (JFCON, $\mathrm{MSB}$, and $\mathrm{PMN})$.

\section{ACKNOWLEDGMENTS}

We thank Dr. Rodrigo Latado (IAC, Cordeirópolis, Brazil) for the transgene copy-number analyses assistance, Prof. Márcia Pinheiro Margis (UFRS, Porto Alegre, Brazil) for provided Oryza sativa cv. Nipponbare seeds, and Dr. Seiichi Toki (National Institute of Agrobiological Sciences, Ibaraki Prefecture, Japan) for the assistance in rice transformation.

\section{SUPPLEMENTARY MATERIAL}

The Supplementary Material for this article can be found online at: https://www.frontiersin.org/articles/10.3389/fpls.2019.00065/ full\#supplementary-material

Altschul, S. F., Madden, T. L., Schaffer, A. A., Zhang, J., Zhang, Z., Miller, W., et al. (1997). Gapped blast and PSI-Blast: a newgeneration of protein database search programs. Nucleic Acids Res. 25, 3389-3402. doi: 10.1093/nar/25.17.3389

Ambavaram, M. M. R., Basu, S., Krishnan, A., Ramegowda, V., Batlang, U., Rahman, L., et al. (2014). Coordinated regulation of photosynthesis in rice increases yield and tolerance to environmental stress. Nat. Commun. 5:5302. doi: $10.1038 /$ ncomms6302

Ambavaram, M. M. R., Krishnan, A., Trijatmiko, K. R., and Pereira, A. (2011). Coordinated activation of cellulose and repression of lignin biosynthesis 
pathways in rice. Plant Physiol. 155, 916-931. doi: 10.1104/pp.110. 168641

Andrade, L. M., Brito, M. S., Peixoto-Junior, R. F., Marchiori, P. E. R., Nobile, P. M., Martins, A. P. B., et al. (2017). Reference genes for normalization of qPCR assays in sugarcane plants under water deficit. Plant Methods 13:28. doi: 10.1186/s13007-017-0178-2

Andrade, L. M., Nobile, P. M., Ribeiro, R. V., Oliveira, J. F. N. C., Figueira, A. V. O., Frigel, L. T. M., et al. (2016). Characterization of PIP2 aquaporins in Saccharum hybrids. Plant Gene. 5, 31-37. doi: 10.1016/j.plgene.2015. 11.004

Bartels, D., and Sunkar, R. (2005). Drought and salt tolerance in plants. Crit. Rev. Plant Sci. 24, 23-58. doi: 10.1080/07352680590910410

Bi, H., Shi, J., Kovalchuk, N., Luang, S., Bazanova, N., Chirkova, L., et al. (2018). Overexpression of the TaSHN1 transcription factor in bread wheat leads to leaf surface modifications, improved drought tolerance and no yield penalty under controlled growth conditions. Plant Cell Environ. 41, 2549-2566. doi: $10.1111 /$ pce. 13339

Biswal, A. K., Hao, Z. Y., Pattathil, S., Yang, X. H., Winkeler, K., Collins, C., et al. (2015). Downregulation of GAUT12 in Populus deltoides by RNA silencing results in reduced recalcitrance, increased growth and reduced xylan and pectin in a woody biofuel feedstock. Biotechnol. Biofuels 8:41. doi: 10.1186/s13068015-0218-y

Biswal, A. K., Soeno, K., Gandla, M. L., Immerzeel, P., Pattathil, S., Lucenius, J., et al. (2014). Aspen pectate lyase Ptxt PL1-27 mobilizes matrix polysaccharides from woody tissues and improves saccharification yield. Biotechnol. Biofuels 7:11. doi: 10.1186/1754-6834-7-11

Bottcher, A., Cesarino, I., Santos, A. B., Vicentini, R., Mayer, J. L. S., Vanholme, R., et al. (2013). Lignification in sugarcane: biochemical characterization, gene discovery and expression analysis in two genotypes contrasting for lignin content. Plant Physiol. 163, 1539-1557. doi: 10.1104/pp.113.22 5250

Brown, L., and Torget, R. (1996). Enzymatic Saccharification of Lignocellulosic Biomass (Golden, CO: NREL Ethanol Project, LAP 009).

Chang, S., Puryear, J., and Cairney, J. A. (1993). Simple and efcient method for isolating RNA from pine trees. Plant Mol. Biol. Rep. 11, 113-116. doi: 10.1007/ BF02670468

Chen, L., Auh, C., Chen, F., Cheng, X., Aljoe, H., Dixon, R. A., et al. (2002). Lignin deposition and associated changes in anatomy, enzyme activity, gene expression, and ruminal degradability in stems of tall fescue at different developmental stages. J. Agric. Food Chem. 50, 5558-5565. doi: 10.1021/ jf020516x

Chen, P., and Peng, L. C. (2013). "The diversity of lignocellulosic biomass resources and their evaluation for use as biofuels and chemicals." in Biological Conversion of Biomass for Fuels and Chemicals: Explorations From Natural Utilization Systems, eds J. Z. Sun, S. Y. Ding, and J. D. Peterson (Oxfordshire: Royal Society of Chemistry), 83-113

CONAB (2018). Acompanhamento de Safra Brasileira de Cana-de-açúcar, v.4 Safra 2017/18, n. 4 - Quarto Levantamento. Brasília: Companhia Nacional De Abastecimento.

de Ollas, C., and Dodd, I. C. (2016). Physiological impacts of ABA-JA interactions under water-limitation. Plant Mol. Biol. 91, 641-650. doi: 10.1007/s11103-0160503-6

De Schutter, K., and Van Damme, E. (2015). Protein-carbohydrate interactions as part of plant defense and animal immunity. Molecules 20, 9029-9053. doi: 10.3390/molecules20059029

Dias, M. O. S., da Cunha, M. P., Maciel Filho, R., Bonomi, A., Jesus, C. D., and Rossell, C. E. (2011). Simulation of integrated first and second generation bioethanol production from sugarcane: comparison between different biomass pretreatment methods. J. Ind. Microbiol. Biotechnol. 38, 955-966. doi: 10.1007/ s10295-010-0867-6

Ding, J., Jia, J., Yang, L., Wen, H., Zhang, C., Liu, W., et al. (2004). Validation of a rice specific gene, sucrose phosphate synthase, used as the endogenous reference gene for qualitative and real-time quantitative PCR detection of transgenes. J. Agric. Food Chem. 52, 3372-3377. doi: 10.1021/jf049915d

Emerson, R., Hoover, A., Ray, A., Lacey, J., Cortez, M., Payne, C., et al. (2014). Drought effects on composition and yield for corn stover, mixed grasses, and Miscanthus as bioenergy feedstocks. Biofuels 5, 275-291. doi: 10.1080/17597269. 2014.913904
Esen, A., and Blanchard, D. J. (2000). A specific beta-glucosidase-aggregating factor is responsible for the beta-glucosidase null phenotype in maize. Plant Physiol. 122, 563-572. doi: 10.1104/pp.122.2.563

Fang, Y., and Xiong, L. (2015). General mechanisms of drought response and their application in drought resistance improvement in plants. Cell. Mol. Life Sci. 72, 673-689. doi: 10.1007/s00018-014-1767-0

FAOSTAT (2013). Food and Agriculture Organization Statistics Database. Available at: http://faostat3.fao.org/faostat-geteway/go/to/home/E [accessed November 10, 2015]

Gall, H. L., Philippe, F., Domon, J.-M., Gillet, F., Pelloux, J., and Rayon, C. (2015). Cell wall metabolism in response to abiotic stress. Plants 4, 112-166. doi: $10.3390 /$ plants4010112

Gascuel, O. (1997). BIONJ: an improved version of the NJ algorithm based on a simple model of sequence data. Mol. Biol. Evol. 14, 685-695. doi: 10.1093/ oxfordjournals.molbev.a025808

Golldack, D., Li, C., Mohan, H., and Probst, N. (2014). Tolerance to drought and salt stress in plants: unraveling the signaling networks. Front Plant Sci. 5:151. doi: $10.3389 /$ fpls. 2014.00151

Hensel, G., Kumlehn, J., Weidenbach, D., Esch, L., Mo, C., and Hu, R. (2016). Polarized defense against fungal pathogens is mediated by the jacalin-related lectin domain of modular Poaceae -specific proteins. Mol. Plant. 9, 514-527. doi: 10.1016/j.molp.2015.12.009

Himmel, M. E., and Bayer, E. A. (2009). Lignocellulose conversion to biofuels: current challenges, global perspectives. Curr. Opin. Biotechnol. 20, 316-317. doi: 10.1016/j.copbio.2009.05.005

Himmel, M. E., Ding, S.-Y., Johnson, D. K., Adney, W. S., Nimlos, M. R., Brady, J. W., et al. (2007). Biomass recalcitrance: engineering plants and enzymes for biofuels production. Science 315, 804-807. doi: 10.1126/science.1137016

Howe, G. A. (2010). Ubiquitin ligase-coupled receptors extend their reach to jasmonate. Plant Physiol. 154, 471-474. doi: 10.1104/pp.110.161190

Hsiao, T. C., O’Toole, J. C., Yambao, E. B., and Turner, N. C. (1984). Influence of osmotic adjustment on leaf rolling and tissue death in rice (Oryza sativa L.) Plant Physiol. 75, 338-341. doi: 10.1104/pp.75.2.338

Inman-Bamber, N. G., and Smith, D. M. (2005). Water relations in sugarcane and response to water deficits. Field Crops Res. 92, 185-202. doi: 10.1016/j.fcr.2005. 01.023

Jiang, J. F., Han, Y., Xing, L. J., Xu, Y. Y., Xu, Z. H., and Chong, K. (2006). Cloning and expression of a novel cDNA encoding a mannosespecific jacalin-related lectin from Oryza sativa. Toxicon 47, 133-139. doi: 10.1016/j.toxicon.2005. 10.010

Jiang, J. F., Xu, Y. Y., and Cong, K. (2007). Overexpression of OsJAC1, a lectin gene, suppresses the coleoptile and stem elongation in rice. J. Integr. Plant Biol. 49, 230-237. doi: 10.1111/j.1744-7909.2007.00428.x

Jiang, S. Y., Ma, Z., and Ramachandran, S. (2010). Evolutionary history and stress regulation of the lectin superfamily in higher plants. BMC Evol. Biol. 10:79. doi: 10.1186/1471-2148-10-79

Jones, D. T., Taylor, W. R., and Thornton, J. M. (1992). The rapid generation of mutation data matrices from protein sequences. Comput. Appl. Biosci. 8, 275-282. doi: 10.1093/bioinformatics/8.3.275

Karaba, A., Dixit, S., Greco, R., Aharoni, A., Trijatmiko, K., Marsch-Martinez, N., et al. (2007). Improvement of water use efficiency in rice by expression of HARDY, an Arabidopsis drought and salt tolerance gene. PNAS 104, 1527015275. doi: 10.1073/pnas.0707294104

Karimi, M., Depicker, A., and Hilson, P. (2007). Recombinational cloning with plant gateway vectors. Plant Physiol. 145, 1144-1154. doi: 10.1104/pp.107. 106989

Kittur, F. S., Yu, H. Y., Bevan, D. R., and Esen, A. (2010). Deletion of the N-terminal dirigent domain in maize beta-glucosidase aggregating factor and its homolog sorghum lectin dramatically alters the sugar-specificities of their lectin domains. Plant Physiol. Biochem. 48, 731-734. doi: 10.1016/j.plaphy.2010.03.007

Kumar, J., Gunapati, S., Kianian, S. F., and Sudhir, P. S. (2018). Comparative analysis of transcriptome in two wheat genotypes with contrasting levels of drought tolerance. Protoplasma 255, 1487-1504. doi: 10.1007/s00709-0181237-x

Kumar, T., Uzma, Khan, M. R., Abbas, Z., and Ali, G. M. (2014). Genetic improvement of sugarcane for drought and salinity stress tolerance using Arabidopsis vacuolar pyrophosphatase (AVP1) gene. Mol. Biotechnol. 56, 199209. doi: 10.1007/s12033-013-9695-Z 
Lannoo, N., and Van Damme, E. J. M. (2010). Nucleocytoplasmic plant lectins. Biochim. Biophys. Acta 1800, 190-201. doi: 10.1016/j.bbagen.2009.07.021

Lionetti, V., Francocci, F., Ferrari, S., Volpi, C., Bellincampi, D., Galletti, R., et al. (2010). Engineering the cell wall by reducing de-methyl-esterified homogalacturonan improves saccharification of plant tissues for bioconversion. Proc. Natl. Acad. Sci. U.S.A. 107, 616-621. doi: 10.1073/pnas.09075 49107

Livak, K. J., and Schmittgen, T. D. (2001). Analysis of relative gene expression data using real-time quantitative PCR and the 2(-Delta Delta C(T)) method. Methods 25, 402-408. doi: 10.1006/meth.2001.1262

Lou, D., Wang, H., Liang, G., and Yu, D. (2017). OsSAPK2 confers abscisic acid sensitivity and tolerance to drought stress in rice. Front. Plant Sci. 8:993. doi: 10.3389/fpls.2017.00993

Ma, Q.-H. (2014). Monocot chimeric jacalins: a novel subfamily of plant lectins. Crit. Rev. Biotechnol. 34, 300-306. doi: org/10.3109/07388551.2013.793650

Ma, Q.-H., Tian, B., and Li, Y.-L. (2010). Overexpression of a wheat jasmonateregulated lectin increases pathogen resistance. Biochimie 92, 187-193. doi: 10. 1016/j.biochi.2009.11.008

Ma, Q.-H., Zhen, W.-B., and Liu, Y.-C. (2013). Jacalin domain in wheat jasmonateregulated protein Ta-JA1 confers agglutinating activity and pathogen resistance. Biochimie 95, 359-365. doi: 10.1016/j.biochi.2012.10.014

Martins, A. P. B., Brito, M. S., Mayer, J. L. S., Llerena, J. P. P., Oliveira, J. F., Takahashi, N. G., et al. (2018). Ectopic expression of sugarcane SHINE changes cell wall and improves biomass in rice. Biomass Bioenergy 119, 322-334. doi: 10.1016/j.biombioe.2018.09.036

Mason, G., Provero, P., Vaira, A. M., and Accotto, G. P. (2002). Estimating the number of integrations in transformed plants by quantitative real-time PCR. BMC Biotechnol. 2:20. doi: 10.1186/1472-6750-2-20

Mitra, J. (2001). Genetics and genetic improvement of drought resistance in crop plants. Curr. Sci. 80, 758-764.

Molinari, H. B. C., Marur, C. J., Daros, E., Campos, M. K. F., Carvalho, J. F. R. P., Bespalhok Filho, J. C., et al. (2007). Evaluation of the stress-inducible production of proline in transgenic sugarcane (Saccharum spp.): osmotic adjustment, chlorophyll fluorescence and oxidative stress. Physiol. Plant. 130, 218-229. doi: 10.1111/j.1399-3054.2007.00909.x

Moore, J. P., Vicré-Gibouin, M., Farrant, J. M., and Driouich, A. (2008). Adaptations of higher plant cell walls to water loss: drought vs desiccation. Physiol. Plant. 134, 237-245. doi: 10.1111/j.1399-3054.2008.01134.x

Muñoz-Espinoza, V. A., López-Climent, M. F., Casaretto, J. A., and Gómez-Cadenas, A. (2015). Water stress responses of tomato mutants impaired in hormone biosynthesis reveal abscisic acid, jasmonic acid and salicylic acid interactions. Front. Plant Sci. 6:997. doi: 10.3389/fpls.2015. 00997

Nobile, P. M., Bottcher, A., Mayer, J. L. S., Brito, M. S., Dos Anjos, I. A., Landell, M. G. A., et al. (2017). Identification, classification and transcriptional profiles of dirigent domain-containing proteins in sugarcane. Mol. Genet. Genomics 292, 1323-1340. doi: 10.1007/s00438-017-1349-6

Noda, S., Koshiba, T., Hattori, T., Yamaguchi, M., Suzuki, S., and Umezawa, T. (2015). The expression of a rice secondary wall-specific cellulose synthase gene, OsCesA7, is directly regulated by a rice transcription factor, OsMYB58/63. Planta 242, 589-600. doi: 10.1007/s00425-015-2343-z

Oliveira, J. F. N. C. (2012). Caracterização Fisiológica E Perfil de Expressão Gênica de Cultivares de Cana-de-Açúcar (Saccharum spp.) Contrastantes Para o Déficit Hidrico. Master's thesis, Centro de Energia Nuclear na Agricultura/Esalq-USP: Piracicaba.

Pauwels, L., Inze, D., and Goossens, A. (2009). Jasmonate-inducible gene: what does it mean? Trends Plant Sci. 14, 87-91. doi: 10.1016/j.tplants.2008.11.005

Peumans, W. J., and Van Damme, E. J. M. (1995). Lectins as plant defense proteins. Plant Physiol. 109, 347-352.

Phitsuwan, P., Sakka, K., and Ratanakhanokchai, K. (2013). Improvement of lignocellulosic biomass in planta: a review of feedstocks, biomass recalcitrance, and strategic manipulation of ideal plants designed for ethanol production and processability. Biomass Bioenergy 58, 390-405. doi: 10.1016/j.biombioe.2013. 08.027

Qing, Q., Yang, B., and Wyman, C. E. (2010). Xyloligomers are strong inhibitors of cellulose hydrolysis by enzymes. Bioresour. Technol. 101, 9624-9630. doi: 10.1016/j.biortech.2010.06.137
Reis, R. R., da Cunha, B. A., Martins, P. K., Martins, M. T., Alekcevetch, J. C., Chalfun, A. Jr., et al. (2014). Induced over-expression of AtDREB2A CA improves drought tolerance in sugarcane. Plant Sci. 221-222, 59-68. doi: 10. 1016/j.plantsci.2014.02.003

Sakurai, N., Tanaka, S., and Kuraishi, S. (1987a). Changes in wall polysaccharides of squash (Cucurbita maxima Duch.) hypocotyl under water stress condition. I. Wall sugar composition and growth as affected by water stress. Plant Cell Physiol. 28, 1051-1058. doi: 10.1093/oxfordjournals.pcp. a077385

Sakurai, N., Tanaka, S., and Kuraishi, S. (1987b). Changes in wall polysaccharides of squash (Cucurbita maxima Duch.) hypocotyls under water stress condition. II. Composition of pectic and hemicellulosic polysaccharides. Plant Cell Physiol. 28, 1059-1070. doi: 10.1093/oxfordjournals.pcp. a077386

Scheller, H. V., and Ulvskov, P. (2010). Hemicelluloses. Annu. Rev. Plant Biol. 61, 263-289. doi: 10.1146/annurev-arplant-042809-112315

Shin, H. D., McClendon, S., Vo, T., and Chen, R. R. (2010). Escherichia coli binary culture engineered for direct fermentation of hemicellulose to a biofuel. Appl. Environ. Microbiol. 76, 8150-8159. doi: 10.1128/AEM.00908-10

Schutter, K., and Van Damme, E. (2015). Protein-carbohydrate interactions as part of plant defense and animal immunity. Molecules 20, 9029-9053. doi: 10.3390/ molecules 20059029

Shinozaki, K., Yamaguchi-Shinozaki, K., and Seki, M. (2003). Regulatory network of gene expression in the drought and cold stress responses. Curr. Opin. Plant Biol. 6, 410-417. doi: 10.1016/S1369-5266(03)00092-X

Song, M., Xu, W., Xiang, Y., Jia, H., Zhang, Z., and Ma, Z. (2014). Association of jacalin-related lectins with wheat responses to stresses revealed by transcriptional profiling. Plant Mol. Biol. 84, 95-110. doi: 10.1007/s11103-0130121-5

Subramanyam, S., Sardesai, N., Puthoff, D. P., Meyer, J. M., Nemacheck, J. A., Gonzalo, M., et al. (2006). Expression of two wheat defense-response genes, Hfr-1 and Wci-1, under biotic and abiotic stresses. Plant Sci. 170, 90-103. doi: 10.1016/j.plantsci.2005.08.006

Subramanyam, S., Smith, D. M., Clemens, J. C., Webb, M. A., Sardesai, N., and Williams, C. E. (2008). Functional characterization of HFR1, a high mannose Nglycan-specific wheat lectin induced by Hessian fly larvae. Plant Physiol. 147, 1412-1426. doi: 10.1104/pp.108.116145

Sweet, W. J., Morrison, J. C., Labavitch, J. M., and Matthews, M. A. (1990). Altered synthesis and composition of cell wall of grape (Vitis vinifera L.) leaves during expansion and growth inhibiting water deficit. Plant Cell Physiol. 31, 407-414. doi: 10.1093/oxfordjournals.pcp.a077924

Tamura, K., Stecher, G., Peterson, D., Filipski, A., and Kumar, S. (2013). MEGA: molecular evolutionary genetics analysis version 6.0. Mol. Biol. Evol. 30, 27252729. doi: 10.1093/molbev/mst197

TAPPI. (1985). TAPPI Useful Method UM 250: Acid-Soluble Lignin in Wood and Plants. TAPPI Useful Methods. Peachtree Corners, GA: TAPPI.

Thompson, D. S. (2005). How do cell walls regulate plant growth? J. Exp. Bot. 56, 2275-2285. doi: 10.1093/jxb/eri247

Thompson, J. D., Higgins, D. G., and Gibson, T. J. (1994). Clustal W: improving the sensitivity of progressive multiple sequence alignment through sequence weighting, positions-specific gap penalties and weight matrix choice. Nucleic Acids Res. 22, 4673-4680. doi: 10.1093/nar/22.22.4673

Tiwari, S., Lata, C., Chauhan, P. S., Prasad, V., and Prasad, M. (2017). A functional genomic perspective on drought signalling and its crosstalk with phytohormone-mediated signalling pathways in plants. Curr. Gen. 18, 469-482. doi: 10.2174/1389202918666170605083319

Toki, S., Hara, N., Ono, K., Onodera, H., Tagiri, A., Oka, S., et al. (2006). Early infection of scutellum tissue with Agrobacterium allows highspeed transformation of rice. Plant J. 47, 969-976. doi: 10.1111/j.1365-313X.2006. 02836.x

Tyagi, A. K., and Mohanty, A. (2000). Rice transformation for crop improvement and functional genomics. Plant Sci. 158, 1-18. doi: 10.1016/S0168-9452(00) 00325-3

Van Damme, E. J. M., Peumans, W. J., Barre, A., and Rougé, P. (1998). Plant lectins: a composite of several distinct families of structurally and evolutionary related proteins with diverse biological roles. Crit. Rev. Plant Sci. 17, 575-692. doi: 10.1080/07352689891304276 
Van Raij, B., Cantarella, H., Spironello, A., Penaltti, C. P., Morelli, J. L., Orlando, J., et al. (1996). "Cana-de-açúcar," in Furlani AMC. Recomendações de Adubação e Calagem Para o Estado de São Paulo, eds B. Van Raij, H. Cantarella, and J. A. Quaggio (Campinas: Instituto Agronomico/IAC), 237-239.

Verslues, P. E., Agarwal, M., Katiyar-Agarwal, S., Zhu, J., and Zhu, J. K. (2006). Methods and concepts in quantifying resistance to drought, salt and freezing, abiotic stresses that affect plant water status. Plant J. 46, 523-539. doi: 10.1111/ j.1365-313X.2005.02593.x

Vijayan, M., and Chandra, N. (1999). Lectins. Curr. Opin. Struct. Biol. 9, 707-714. doi: 10.1016/S0959-440X(99)00034-2

Wakabayashi, K., Hoson, T., and Kamisaka, S. (1997). Changes in amounts and molecular mass distribution of cell wall polysaccharides of wheat (Triticum aestivum L.) coleoptiles under water stress. J. Plant Physiol. 151, 33-40. doi: 10.1016/S0176-1617(97)80033-8

Walley, J. W., and Dehesh, K. (2010). Molecular mechanisms regulating rapid stress signaling networks in Arabidopsis. J. Integr. Plant Biol. 52, 354-359. doi: $10.1111 / j .1744-7909.2010 .00940 . x$

Wang, X. M., and Ma, Q. H. (2005). Characterization of a jasmonateregulated wheat protein related to a beta-glucosidase-aggregating factor. Plant Physiol. Biochem. 43, 185-192. doi: 10.1016/j.plaphy.2005. 01.018

Wasternack, C. (2007). Jasmonates: an update on biosynthesis, signal, transduction and action in plant stress response, growth and development. Ann. Bot. 100, 681-697. doi: 10.1093/aob/mcm079

Wasternack, C., and Hause, B. (2013). Jasmonates: biosynthesis, perception, signal transduction and action in plant stress response, growth and development. an update to the 2007 review in annals of botany. Ann. Bot. 111, 1021-1058. doi: $10.1093 / \mathrm{aob} / \mathrm{mct} 067$

Williams, C. E., Collier, C. C., Nemacheck, J. A., Liang, C., and Cambron, S. E. (2002). A lectin-like gene responds systemically to attempted feeding by avirulent first-instar Hessian fly larvae. J. Chem. Ecol. 28, 1411-1428. doi: 10.1023/A:1016200619766

Xiang, Y., Tang, N., Du, H., Ye, H., and Xiong, L. (2008). Characterization of OsbZIP23 as a key player of the basic leucine zipper transcription factor family for conferring abscisic acid sensitivity and salinity and drought tolerance in rice. Plant Physiol. 148, 1938-1952. doi: 10.1104/pp.108. 128199
Xiao, B., Huang, Y., Tang, N., and Xiong, L. (2007). Over-expression of a LEA gene in rice improves drought resistance under the field conditions. Theor. Appl. Genet. 115, 35-46. doi: 10.1007/s00122-007-0538-9

Xiao, J., Cheng, H., Li, X., Xiao, J., Xu, C., and Wang, S. (2013). Rice WRKY13 regulates cross talk between abiotic and biotic stress signaling pathways by selective binding to different cis-elements. Plant Physiol. 163, 1868-1882. doi: 10.1104/pp.113.226019

Xu, K., Chen, S., Li, T., Ma, X., Liang, X., Ding, X., et al. (2015). OsGRAS23, a rice GRAS transcription factor gene, is involved in drought stress response through regulating expression of stress-responsive genes. BMC Plant Biol. 15:141. doi: 10.1186/s12870-015-0532-3

Zhang, S. Z., Yang, B. P., Feng, C. L., Chen, R. K., Luo, J. P., Wen-Wei, C., et al. (2006). Expression of the Grifola frondosa trehalose synthase gene and improvement of drought-tolerance in sugarcane (Saccharum officinarum L.). J. Integrat. Plant Biol. 48, 453-459. doi: 10.1111/j.1744-7909.2006.00246.x

Zhang, Y. X., and Chen, L. (2017). Overexpression of the receptor-like kinase gene OsNRRB enhances drought-stress tolerance in rice. Euphytica 213:86. doi: 10.1007/s10681-017-1854-z

Zhao, D., and Li, Y.-R. (2015). Climate change and sugarcane production: potential impact and mitigation strategies. Int. J. Agron. 2015:547386. doi: 10.1155/2015/ 547386

Zhou, J., Lee, C., Zhong, R., and Ye, Z. H. (2009). MYB58 and MYB63 are transcriptional activators of the lignin biosynthetic pathway during secondary cell wall formation in Arabidopsis. Plant Cell. 21, 248-266. doi: 10.1105/tpc.108. 063321

Conflict of Interest Statement: The authors declare that the research was conducted in the absence of any commercial or financial relationships that could be construed as a potential conflict of interest.

Copyright (® 2019 Andrade, Peixoto-Junior, Ribeiro, Nóbile, Brito, Marchiori, Carlin, Martins, Goldman, Llerena, Fregonesi, Perecin, Nebó, Figueira, Benatti, Silva, Mazzafera and Creste. This is an open-access article distributed under the terms of the Creative Commons Attribution License (CC BY). The use, distribution or reproduction in other forums is permitted, provided the original author(s) and the copyright owner(s) are credited and that the original publication in this journal is cited, in accordance with accepted academic practice. No use, distribution or reproduction is permitted which does not comply with these terms. 